\title{
Effects of Preoperative Oral Carbohydrate Loading on Preoperative and Postoperative Comfort in Patients Planned to Undergo Elective Cholecystectomy: A Prospective Randomized Controlled Clinical Trial
}

\author{
Mehmet Ali Gök ${ }^{1}$, Mehmet Tolga Kafadar, ${ }^{2 *}$ (iD) and Serkan Fatih Yeğen ${ }^{3}$ \\ ${ }^{1}$ Health Sciences University Derince Training and Research Hospital Clinic of General Surgery, Kocaeli, Turkey \\ 2 Dicle University School of Medicine, Department of General Surgery, Diyarbakır, Turkey \\ ${ }^{3}$ Ali Osman Sönmez Oncology Hospital Clinic of General Surgery, Bursa, Turkey
}

* Corresponding author: Mehmet Tolga Kafadar, Dicle University School of Medicine, Department of General Surgery, Diyarbakır, Turkey. Tel: + 904122488001-4679; Email: drtolgakafadar@hotmail.com

Received 2020 August 18; Revised 2020 September 20; Accepted 2020 0ctober 15.

\begin{abstract}
Background: Cholecystectomy is a widespread abdominal procedure. A period of 8-hour-fasting for this relatively rapid surgery negatively affects the patients' comfort.

Objectives: The current study aimed to evaluate the effects of the presurgical intake of carbohydrates on patients' comfort.

Methods: This prospective study was carried out on 42 cholecystectomy patients (with the American Society of Anesthesiologists grade of I-II) divided into two groups. The patients in group 1 underwent laparoscopic cholecystectomy after an 8-hour-fasting period. The subjects in group 2 received a carbohydrate-rich solution with $12.5 \%$ dextrose before the surgery (125 g of sugar melted in $1 \mathrm{~L}$ of water; 800 and $200 \mathrm{~mL} 8$ and $2 \mathrm{~h}$ before the surgery, respectively). Thirst, hunger, and nausea at the 9 th preoperative hour and $30 \mathrm{~min}$ before the surgery in addition to nausea and vomiting at the $2^{\text {nd }}$, $8^{\text {th }}$, and $24^{\text {th }}$ postoperative hours were assessed in both groups.

Results: The mean age and body mass index (BMI) values of the patients were $48.38 \pm 12.68$ years and $29.85 \pm 5.20 \mathrm{~kg} / \mathrm{m}^{2}$ respectively. The mean operational time was $36.5 \mathrm{~min}$ (range: 26-114 min). No difference was observed between the two groups in terms of age, BMI, and operational time. The investigation $30 \mathrm{~min}$ before cholecystectomy revealed that the rates of hungry and thirsty patients were higher in group 1 , compared to those reported for group $2(\mathrm{P}=0.003$ and $\mathrm{P}=0.032)$. Nevertheless, at the $2^{\text {nd }}$ and $8^{\text {th }}$ postoperative hours, the rate of patients' complaining of nausea was higher in group 2 in comparison to that of group 1 ( $\mathrm{P}=0.048$ and $\mathrm{P}=0.014$ ).

Conclusion: It is suggested that the intake of carbohydrate-rich fluids up to the preoperative $2^{\text {nd }}$ hour decreased presurgical hunger/thirst. The results of this study are in line with the findings of previous studies. It is believed that the intake of CHO-rich solutions up to $2 \mathrm{~h}$ before surgery may provide comfort by decreasing hunger/thirst. Nevertheless, it is necessary to take into account a potential rise in a feeling of nausea among these patients.
\end{abstract}

Keywords: Carbohydrate, Laparoscopic cholecystectomy, Preoperative fasting

\section{Background}

Since previous decades, 8-hour-total preoperative fasting has remained a routine procedure to avoid aspiration pneumonia due to the regurgitation of gastric contents in perioperative and postoperative periods. Moreover, this preoperative fasting is still considered a necessity in many hospitals $(1,2)$. However, in recent years, most studies have recommended radical modifications in the fasting policy; accordingly, the standard approach of absolute fasting since midnight is now becoming more and more flexible allowing a period of limited fluid, with or without carbohydrate, intake up to $2 \mathrm{~h}$ before surgical intervention (3-5). Transit periods of carbohydrate-rich solutions from the stomach to duodenum are shorter than $2 \mathrm{~h}$ (1).

Nowadays, it is well known that presurgical oral food replacement with carbohydrate-rich fluids may decrease both preoperative and postoperative thirst and hunger in all age groups (3). Moreover, many randomized controlled trials have demonstrated the reduction of nausea and vomiting due to the use of oral CHO solutions before surgery (6-8). In addition, current studies have reported that shortening the fasting period with preoperative oral CHO-rich solutions has a positive effect on postoperative stress and recovery by decreasing insulin resistance, sparing the muscle proteins, and preserving the functions of the immune system (9-11).

\section{Objectives}

Obviously, cholelithiasis is one of the most prevalent gastroenterological pathology (12). Laparoscopic cholecystectomy is extensively applied in routine general and visceral surgical practice; therefore, the current study aimed to evaluate the efficacy of reducing the preoperative fasting period using oral CHO-rich solutions in the thirst, hunger, nausea, and vomiting of patients undergoing elective cholecystectomy. 


\section{Methods}

The present study was carried out on 4 male and 38 female patients with the American Society of Anesthesiologists (ASA) grade of I-II within the age range of 18-70 years undergoing elective laparoscopic cholecystectomy due to symptomatic cholelithiasis. The patients with a body mass index (BMI) of over $40 \mathrm{~kg} / \mathrm{m}^{2}$, need for an additional intervention (e.g., perioperative cholangiography due to concomitant common bile duct stones), acute/ chronic cholecystitis and serious comorbidities (e.g., diabetes mellitus, endocrine disorders, cardiovascular pathologies, neurologic and/or psychiatric diseases, hepatic failure, obstructive jaundice, and additional gastrointestinal disorders), and previous visceral abdominal surgeries were excluded from the study to ensure the homogeneity. In addition, the patients who had reflux or indigestion history and were under pharmacotherapy which could affect the gastrointestinal motility were excluded from the study. All the included subjects were operated on before 11.00 a.m. on the day of the surgery.

The patients were divided into two groups, one by one, according to the administration of carbohydrate and fasting. The study subjects in group $1(n=21)$ were fasting since midnight. The participants in group $2(n=21)$ received peroral $\mathrm{CHO}$-rich solution with $12.5 \%$ dextrose (125 g of granulated sugar melted in $1 \mathrm{~L}$ of drinking water; 800 and $200 \mathrm{~mL} 8$ and $2 \mathrm{~h}$ before the surgery, respectively).

In order to properly evaluate differences between both groups, the patients from each group were chosen by a computerized randomization program on the previous day before the surgery. All the participants were operated on within 09:00 and 12:00 a.m. All the patients were scheduled for elective standard 4-port-access laparoscopic cholecystectomy, with a standard $13 \mathrm{mmHg}$ intraabdominal pressure. In addition, the length of hospital stay was reported as $24 \mathrm{~h}$. The intraabdominal $\mathrm{CO}_{2}$ was evacuated at the end of the operation from the umbilical access port.

For standardization, the patients received no premedication before the surgery. Routine general anesthesia was induced with intravenous thiopental (5 mg/kg), fentanyl ( $1 \mu \mathrm{g} / \mathrm{kg}$ ), and rocuronium $(0.6$ $\mathrm{mg} / \mathrm{kg}$ ). During the surgery, anesthesia was maintained using $65 \%$ nitrous oxide and $1 \%$ sevoflurane in $35 \%$ oxygen with the help of an endotracheal tube. At the end of the surgery, perioperative curarization was antagonized by neostigmine and atropine. Ringer lactate solution was used for intraoperative and postoperative fluid replacement in both groups. The study subjects were allowed to drink and eat at the $6^{\text {th }}$ and $8^{\text {th }}$ postoperative hours, respectively. The patients received intravenous tramadol treatment for analgesia during the first $24 \mathrm{~h}$.
The main assessed criteria in this study were thirst, hunger, and nausea (at the $9^{\text {th }}$ preoperative hour and $30 \mathrm{~min}$ before the surgery) in addition to nausea and vomiting (at the $2^{\text {nd }}, 8^{\text {th }}$, and $24^{\text {th }}$ postoperative hours). The age, gender, BMI, and operational time of all the patients were also evaluated in the present study.

\subsection{Study limitations}

The major limitation of the current trial was the lack of a placebo group. In several clinical randomized controlled studies on this topic, the patients were divided into three control, placebo, and oral intake groups. Multivariate analysis between the control, oral $\mathrm{CHO}$ intake, and placebo groups would provide more accurate data on the efficacy of preoperative $\mathrm{CHO}$-rich fluids. Another limitation was the relatively low number of patients. However, these controversial results of the present pilot trial encouraged the authors to design other prospective clinical controlled studies with a larger sample size. Furthermore, insulin resistance, anxiety, and recovery were not evaluated in this study; nevertheless, they were assessed in several studies. Therefore, the simplicity of the study might be considered a relative limitation. Additionally, the authors believed that the investigation of a limited number of variables within a strictly homogenized trial allowed achieving more precise data.

\subsection{Statistical analysis}

The statistical analyses were performed using SPSS software (Statistical Package for the Social Sciences; version 21.0; SPSS Inc., Chicago, Illinois, USA). Descriptive statistics were reported as mean \pm standard deviation for normally distributed variables and median (minimum-maximum) for nonnormally distributed variables. For the categorical data, descriptive variables were reported as frequency and percentage. The Mann-Whitney U test and independent samples t-test were used for the intergroup comparisons of the continuous variables. The comparison of the categorical variables was conducted using Fisher's exact test, Chi-square test, and Yates' correction for continuity. Spearman's rank correlation coefficient was used for the calculation of the relationship between the variables. In all statistical tests, an $\alpha$ value of 0.05 and a p-value of less than 0.05 were considered statistically significant.

All the patients scheduled for laparoscopic cholecystectomy in Ali Osman Sönmez Oncology Hospital Clinic of General Surgery, Bursa, Turkey, were prospectively included in this study. The present study was conducted according to the principles of the Declaration of Helsinki (Ethical Principles for Medical Research Involving Human Subjects) developed by the World Medical Association (modified in October 2013). This study 
was approved by the Ethics Committee of Bursa Yüksek İhtisas Training and Research Hospital in Turkey (Approval/RCT no.: 2011-KAEK-25 2015/2402). Written informed consent was obtained from the patients who participated in this study.

\section{Results}

A total of 42 patients were included in this clinical trial. In addition, 4 (9.5\%) and 38 (90.5\%) participants were male and female, respectively. The mean age and BMI values of the patients were $48.38 \pm 12.68$ years and $29.85 \pm 5.20 \mathrm{~kg} / \mathrm{m}^{2}$, respectively. The median operational time was reported as $36.5 \mathrm{~min}$ (range: 26-114 $\mathrm{min}$ ). No statistical difference was observed between the groups in terms of age, BMI, and operational time (Table 1).

At the first investigation of patients (i.e., $9 \mathrm{~h}$ before cholecystectomy), there was no statistical difference between the two groups in thirst, hunger, and nausea. On the other hand, the second investigation (i.e., $30 \mathrm{~min}$ before cholecystectomy) revealed that the rates of hungry and thirsty patients were higher in group 1 than those reported for group 2 with patients undergoing oral replacement with CHO-enriched fluid $(\mathrm{P}=0.003$ and $\mathrm{P}=0.032)$. Statistical analysis did not show any differences between the groups in terms of nausea at the second preoperative investigation (Table 2).

The statistical analysis of the data recorded 2 and $8 \mathrm{~h}$ after the surgery demonstrated a significant difference between the groups regarding nausea. At the $2^{\text {nd }}$ and $8^{\text {th }}$ postoperative hours, the rate of patients complaining of nausea was higher in group 2 , compared to that reported for group $1(\mathrm{P}=0.048$ and $\mathrm{P}=0.014)$. No statistically significant difference was observed between the groups with regard to postoperative vomiting (Table 2). No correlation was observed between the age and BMI parameters and both preoperative and postoperative thirst, hunger, and nausea. Statistical analysis showed that operational time did not have any effects on postoperative thirst, hunger, and nausea.

\begin{tabular}{|c|c|c|c|c|}
\hline & $\begin{array}{c}\text { Group } 1 \\
\text { (Fasting) n (\%) }\end{array}$ & $\begin{array}{c}\text { Group } 2 \\
\text { (Carbohydrate intake) n (\%) }\end{array}$ & Overall & P-value \\
\hline Gender & $20(47.6)$ & 18 (42.9) & $38(90.5)$ & \\
\hline $\begin{array}{l}\text { Age } \\
\text { (year) }\end{array}$ & $\begin{array}{l}50.00 \pm 14.24 \\
(27-70)\end{array}$ & $\begin{array}{c}46.76 \pm 11.01 \\
(18-69)\end{array}$ & $48.38 \pm 12.68$ & $0.415^{*}$ \\
\hline $\begin{array}{l}\text { Body mass index } \\
\left(\mathrm{kg} / \mathrm{m}^{2}\right)\end{array}$ & $\begin{array}{c}29.69 \pm 4.73 \\
(22.80-37.10)\end{array}$ & $\begin{array}{c}30.01 \pm 5.74 \\
(17.96-39.95)\end{array}$ & $29.85 \pm 5.20$ & $0.848^{*}$ \\
\hline $\begin{array}{l}\text { Operational time } \\
\text { (minute) }\end{array}$ & $\begin{array}{c}34.00 \\
(26.00-89.00) \\
\end{array}$ & $\begin{array}{c}37.00 \\
(26.00-114.00)\end{array}$ & $\begin{array}{c}36.5 \\
(26-114) \\
\end{array}$ & $0.724^{* *}$ \\
\hline
\end{tabular}

* Student's t-test

** Mann-Whitney U test

\begin{tabular}{|c|c|c|c|c|c|c|}
\hline & & & $\begin{array}{c}\text { Group 1 } \\
\text { (Fasting) }\end{array}$ & $\begin{array}{c}\text { Group } 2 \\
\text { (Carbohydrate intake) }\end{array}$ & $\begin{array}{c}\text { Overall } \\
\text { n (\%) }\end{array}$ & P-value \\
\hline \multirow{6}{*}{$\begin{array}{l}9 \mathrm{~h} \\
\text { before surgery }\end{array}$} & \multirow[b]{2}{*}{ Thirst } & + & 1 & 0 & $1(2.4)$ & \multirow[b]{2}{*}{ 0.999* } \\
\hline & & - & 20 & 21 & $41(97.6)$ & \\
\hline & \multirow{2}{*}{ Hunger } & + & 2 & 0 & $2(4.8)$ & \multirow{2}{*}{$0.448^{*}$} \\
\hline & & - & 19 & 21 & $40(95.2)$ & \\
\hline & \multirow[b]{2}{*}{ Nausea } & + & 0 & 0 & $0(0)$ & \multirow{2}{*}{$0.999(1.000)^{*}$} \\
\hline & & - & 21 & 21 & $42(100)$ & \\
\hline \multirow{6}{*}{$\begin{array}{l}30 \mathrm{~min} \\
\text { before surgery }\end{array}$} & \multirow{2}{*}{ Thirst } & + & 19 & 12 & 31 (73.8) & \multirow{2}{*}{$0.032^{*}$} \\
\hline & & - & 2 & 9 & $11(26.2)$ & \\
\hline & \multirow{2}{*}{ Hunger } & + & 19 & 9 & $28(66.7)$ & \multirow{2}{*}{$0.003^{* *}$} \\
\hline & & - & 2 & 12 & $14(33.3)$ & \\
\hline & \multirow{2}{*}{ Nausea } & + & 8 & 3 & $11(26.2)$ & \multirow{2}{*}{$0.057^{* *}$} \\
\hline & & - & 13 & 18 & $31(73.8)$ & \\
\hline \multirow{4}{*}{$\begin{array}{l}2 \mathrm{~h} \\
\text { after surgery }\end{array}$} & \multirow{2}{*}{ Nausea } & + & 16 & 21 & $37(88.1)$ & \multirow{2}{*}{$0.048^{*}$} \\
\hline & & - & 5 & 0 & $5(11.9)$ & \\
\hline & \multirow{2}{*}{ Vomiting } & + & 7 & 13 & $20(47.6)$ & \multirow{2}{*}{$0.122^{* *}$} \\
\hline & & - & 14 & 8 & $22(52.4)$ & \\
\hline \multirow{4}{*}{$\begin{array}{l}8 \mathrm{~h} \\
\text { after surgery }\end{array}$} & \multirow{2}{*}{ Nausea } & + & 6 & 15 & $21(50)$ & \multirow{2}{*}{$0.014^{* *}$} \\
\hline & & - & 15 & 6 & $21(50)$ & \\
\hline & \multirow{2}{*}{ Vomiting } & + & 2 & 7 & $9(21.4)$ & \multirow{2}{*}{$0.130^{*}$} \\
\hline & & - & 19 & 14 & $33(78.6)$ & \\
\hline \multirow{4}{*}{$\begin{array}{l}24 \mathrm{~h} \\
\text { after surgery }\end{array}$} & \multirow{2}{*}{ Nausea } & + & 1 & 6 & 7 (16.7) & \multirow{2}{*}{ 0.093* } \\
\hline & & - & 20 & 15 & $35(83.3)$ & \\
\hline & \multirow{2}{*}{ Vomiting } & + & 0 & 0 & $0(0)$ & \multirow{2}{*}{$0.999(1.000)^{*}$} \\
\hline & & - & 21 & 21 & $42(100)$ & \\
\hline
\end{tabular}

* Fisher's exact test

** Yates' correction for continuity 


\begin{tabular}{lcccc}
\hline Table 3. Correlations between assessed criteria & & & \\
\hline & $\begin{array}{c}\text { Thirst } \\
\mathbf{9} \text { h } \\
\text { before surgery }\end{array}$ & $\begin{array}{c}\text { Thirst } \\
\mathbf{3 0} \text { min } \\
\text { before surgery }\end{array}$ & $\begin{array}{c}\text { Nausea } \\
\mathbf{3 0} \text { min } \\
\text { before surgery }\end{array}$ & $\begin{array}{c}\text { Vomiting } \\
\mathbf{8} \mathbf{~ h} \\
\text { after surgery }\end{array}$ \\
\hline $\begin{array}{l}\text { Hunger } \\
\text { before surgery }\end{array}$ & $\mathrm{P}=0.000$ & $\mathrm{P}=0.445$ & $\mathrm{P}=0.400$ & $\mathrm{P}=0.155$ \\
$\begin{array}{l}\text { Hunger } \\
\text { 30 min } \\
\text { before surgery }\end{array}$ & $r=0.698$ & $r=0.121$ & $r=0.133$ & $r=0.224$ \\
$\begin{array}{l}\text { Thirst } \\
\text { 30 min } \\
\text { before surgery }\end{array}$ & $\mathrm{P}=0.486$ & $\mathrm{P}=0.000$ & $\mathrm{P}=0.048$ & $\mathrm{P}=0.016$ \\
\hline
\end{tabular}

Negative correlations between thirst and hunger complaints investigated just before the surgery and vomiting at the $8^{\text {th }}$ postoperative hour were shown by statistical analysis $(\mathrm{P}=0.016, \mathrm{r}=-0.369 ; \mathrm{P}=0.024$, $\mathrm{r}=-0.349)$. Table 3 tabulates statistically significant correlations among the parameters of thirst, hunger, nausea, and vomiting.

\section{Discussion}

Fast track surgery, which is a multidisciplinary approach to facilitate and quicken the recovery period, has become more and more substantial in major surgical practice since the early 90's (13). Nowadays, it is well known that fast-track protocols reduce complication rates and improve functional recovery (13-15). In this concept, patient care is categorized into three stages of before, during, and after surgery. The preoperative phase of fast track procedures includes preoperative fasting and carbohydrate treatment protocols. The Enhanced Recovery After Surgery (ERAS) guidelines recommended an oral intake of clear liquids up to $2 \mathrm{~h}$ before elective surgery and reported that it did not increase gastric residual volume. Based on the guidelines, it is also advised that patients without diabetes should be loaded with preoperative oral carbohydrate solutions before major surgeries (16-18).

Despite recent meta-analyses and reviews, it is hard not to follow the old "nil after midnight" fasting protocol for many surgeons and anesthesiologists. The main reason for strict fasting policies is to avoid perioperative aspiration complications (19). Accelerated Total Postoperative Recovery, a worldwide patient care project based on the clinical trials carried out by ASA and ERAS, restricts solid oral alimentation intake $6 \mathrm{~h}$ before anesthesia and suggests a $200 \mathrm{ml}$ intake of clear fluid increased by $12 \%$ maltodextrin $(20)$.

A review study carried out by Ludwig et al. (20) in 2013 analyzed 38 randomized clinical trials. According to the results of the aforementioned study, it was concluded that the reduction of the presurgical fasting period with a high carbohydrate solution did not pose any risk of morbidity or mortality due to regurgitation/aspiration. Likewise, Manchikanti et al. (21) reported that reduced duration of preoperative fasting did not increase the risk of respiratory depression.

Moreover, some studies demonstrated that the gastric ingredient volume of most participants who have been preoperatively drinking clear fluids (e.g., water) was lower than that of the subjects with conventional fasting regimen $(20,22,23)$. It has been proven for more than 2 decades that the gastric transition time of $400-\mathrm{mL} 285$ mOsm CHO solution was completed in $90 \mathrm{~min}$ (24). In the current study, none of the patients suffered from any complications due to the regurgitation or aspiration of gastric contents.

It is demonstrated that a shortened fasting period with CHO-rich enteral fluid supplement reduces preoperative thirst, hunger, and nausea related to these two unfavorable sensations (4-8, 20, 24-28). As expected, consistent with the findings of almost every study in this regard, the current study achieved similar results in terms of preoperative thirst and hunger. In the reduced fasting duration group, the rates of thirst and hunger were significantly lower than those reported for the group of classical long fasting duration. There was no statistical difference between the groups in terms of preoperative nausea; however, the significance level was observed to be 0.057 .

According to most of the randomized controlled clinical studies in this regard, an intake of $\mathrm{CHO}$ drinks up to $2 \mathrm{~h}$ before surgery reduces also the early postoperative discomfort due to thirst, hunger, nausea, and vomiting $(1-3,8,10,22,29,30)$. On the other hand, no statistically significant difference was observed between the two groups in terms of postoperative vomiting rate. Furthermore, in the present study, it was shown that early postsurgical nausea complaint (i.e., at the $2^{\text {nd }}$ and $8^{\text {th }}$ postoperative hours) was significantly higher in the presurgical CHO-rich fluid intake group, compared to that of the other group.

The reduction of preoperative fasting time and oral intake of $\mathrm{CHO}$ solution up to $2 \mathrm{~h}$ before surgery provides many benefits in the postoperative period. For example, in a clinical prospective controlled study, Ozdemir et al. (31) reported that CHO-rich solutions reduced not only the severity of thirst, hunger, and postoperative nausea and vomiting but 
also insulin resistance and related surgical stress response. They emphasized that the normalization of the preoperative levels of blood glucose with the help of CHO drinks would ensure the safety of general anesthesia and minimize the postoperative catabolic response induced by the increased stress hormones due to operational trauma (31).

In a Cochrane review carried out by Smith et al. (10), the shortened duration of hospital stay in patients undergoing $\mathrm{CHO}$ treatment before elective surgery was compared to that of patients with placebo or fasting since midnight. Smith et al. concluded that the preoperative consumption of high CHO drinks would improve postoperative recovery. Perrone et al. (32) in a study with a very large sample size reported the successful reducing effect of presurgical supplementation with combined $\mathrm{CHO}$ whey protein solutions on postoperative acute phase response and insulin resistance.

In another study, Yildiz et al. (33) claimed that anxiety and depression rates were lower in patients undergoing an oral replacement of CHO-rich fluids before elective cholecystectomy. In addition, the rate of surgery-related fatigue was higher in patients fasting $8 \mathrm{~h}$ before the surgery (33). The possible reasons for reduced postoperative weakness and anxiety rates in the presurgical $\mathrm{CHO}$ group were a decrease in complaints, such as nausea, vomiting, thirst, and hunger, and an increase in patient comfort.

\section{Conclusion}

Almost every study in this regard supports the reduction of the preoperative fasting period which is an old and pointless clinical routine. The best choice to shorten the fasting period seems to be the peroral consumption of $\mathrm{CHO}$-rich clear fluids up to 2 $\mathrm{h}$ before surgery. It was concluded that the oral intake of drinking water with $12.5 \%$ dextrose up to $2 \mathrm{~h}$ before surgery improves the comfort of patients undergoing laparoscopic cholecystectomy by reducing preoperative hunger and thirst. However, in contrast to the results of previous studies, the rates of nausea at the $2^{\text {nd }}$ and $8^{\text {th }}$ postsurgical hours were higher in patients receiving preoperative $\mathrm{CHO}$ rich solution in comparison to those reported for the subjects in the other group.

The controversial results of the present trial should be further discussed; therefore, the authors are planning for another similar study with a larger sample size to confirm the results of the current study. Nevertheless, regarding the proven benefits of reducing the fasting period with $\mathrm{CHO}$ solutions, it is still believed that the aforementioned preoperative protocol should be standardized in every surgery clinic. On the other hand, clinicians should also pay close attention to potential early postoperative nausea due to the preoperative intake of $\mathrm{CHO}$-rich solutions.

\section{Footnotes}

Authors' Contribution: Concept: MAG; Design: MAG and MTK; Supervision: SFY; Funding: MAG, MTK, and SFY; Materials: SFY; Data Collection and/or Processing: MAG and SFY; Analysis and/or Interpretation: MAG and MTK; Literature Review: MTK; Writing: MAG and MTK; Critical Review: MTK

Conflict of Interests: The authors declare that there is no conflict of interest.

Ethical Approval: This study was approved by the Ethics Committee of Bursa Yüksek İhtisas Training and Research Hospital in Turkey (Approval/RCT no.: 2011-KAEK-25 2015/24-02).

Funding/Support: The current study was financially supported by no institution.

Informed consent: Written informed consent was obtained from all the patients who participated in this study.

\section{References}

1. Yilmaz N, Cekmen N, Bilgin F, Erten E, Ozhan MÖ, Coşar A. Preoperative carbohydrate nutrition reduces postoperative nausea and vomiting compared to preoperative fasting. J Res Med Sci. 2013;18(10):827-32. [PubMed: 244977788851].

2. Crenshaw JT, Winslow EH. Preoperative fasting: old habits die hard. Am J Nurs. 2002;102(5):36-44;quiz 45. doi: 10.1097/00000446-200205000-00033. [PubMed: 12006853].

3. Pimenta GP, de Aguilar-Nascimento JE. Prolonged preoperative fasting in elective surgical patients: why should we reduce it? Nutr Clin Pract. 2014;29(1):22-8. doi: 10.1177/08845336 13514277. [PubMed: 24336400]

4. Brady M, Kinn S, Stuart P. Preoperative fasting for adults to prevent perioperative complications. Cochrane Database Syst Rev. 2003;(4):CD004423. doi: 10.1002/14651858.CD004423. [PubMed: 14584013].

5. Brady M, Kinn S, Ness V, O'Rourke K, Randhawa N, Stuart P. Preoperative fasting for preventing perioperative complications in children. Cochrane Database Syst Rev. 2009;(4):CD005285. doi: 10.1002/14651858.CD005285.pub2. [PubMed: 19821343].

6. Power S, Kavanagh DO, McConnell G, Cronin K, Corish C, Leonard $\mathrm{M}$, et al. Reducing preoperative fasting in elective adult surgical patients: a case-control study. Ir $J$ Med Sci. 2012;181(1):99-104. doi: 10.1007/s11845-011-0765-6. [PubMed: 21959951].

7. Hausel J, Nygren J, Thorell A, Lagerkranser M, Ljungqvist 0 . Randomized clinical trial of the effects of oral preoperative carbohydrates on postoperative nausea and vomiting after laparoscopic cholecystectomy. Br J Surg. 2005;92(4):415-21. doi: 10.1002/bjs.4901. [PubMed: 15739210].

8. Singh BN, Dahiya D, Bagaria D, Saini V, Kaman L, Kaje V, et al. Effects of preoperative carbohydrates drinks on immediate postoperative outcome after day care laparoscopic cholecystectomy. Surg Endosc. 2015;29(11):3267-72. doi: 10.1007/s00464-015-4071-7. [PubMed: 25609319].

9. Nygren J, Thorell A, Ljungqvist 0 . Preoperative oral carbohydrate therapy. Curr Opin Anaesthesiol. 2015;28(3): 364-9. doi: 10.1097/ACO.0000000000000192. [PubMed: 25827282].

10. Smith MD, McCall J, Plank L, Herbison GP, Soop M, Nygren J. Preoperative carbohydrate treatment for enhancing recovery after elective surgery. Cochrane Database Syst Rev. 2014; (8):CD009161. doi: 10.1002/14651858.CD009161.pub2. [PubMed: 25121931].

11. Zelić M, Štimac D, Mendrila D, Tokmadžić VS, Fišić E, Uravić M, et al. Preoperative oral feeding reduces stress response after laparoscopic cholecystectomy. Hepatogastroenterology. 2013; 
60(127):1602-6. [PubMed: 24634929].

12. Tihan D, Kafa IM, Duman U, Erol F, Dilektasli E, Dogan G, et al. The effect of morphometric and anatomic relationship of gallbladder to the liver on standard laparoscopic cholecystectomies and proposal of a new anatomical classification. Eur Rev Med Pharmacol Sci. 2016;20(8):1458-66. [PubMed: 27160115].

13. Nanavati AJ, Prabhakar S. Fast-track surgery: Toward comprehensive peri-operative care. Anesth Essays Res. 2014; 8(2):127-33. doi: 10.4103/0259-1162.134474. [PubMed: 25886214].

14. Ansari D, Gianotti L, Schröder J, Andersson R. Fast-track surgery: procedure-specific aspects and future direction. Langenbecks Arch Surg. 2013;398(1):29-37. doi: 10.1007/ s00423-012-1006-9. [PubMed: 23014834].

15. Schwenk W. [Fast-track: evaluation of a new concept]. Chirurg. 2012;83(4):351-5. doi: 10.1007/s00104-011-2226-1. [PubMed: 22415488].

16. Gustafsson UO, Scott MJ, Schwenk W, Demartines N, Roulin D, Francis N, et al. Guidelines forperioperative carein elective colonic surgery: Enhanced Recovery After Surgery (ERAS®) Society recommendations. Clin Nutr. 2012;31(6):783-800. doi: 10.1016/j.clnu.2012.08.013. [PubMed: 23099039].

17. Nygren J, Thacker J, Carli F, Fearon KC, Norderval S, Lobo DN, et al. Guidelines for perioperative care in elective rectal/pelvic surgery: Enhanced recovery after surgery (ERAS®) society recommendations. Clin Nutr. 2012;31(6):801-16. doi: 10.1016/j.clnu.2012.08.012. [PubMed: 23062720].

18. Lassen K, Coolsen MM, Slim K, Carli F, de Aguilar-Nascimento JE, Schäfer M, et al. Guidelines for perioperative care for pancreaticoduodenectomy: Enhanced recovery after surgery (ERAS $\AA$ ) society recommendations. Clin Nutr. 2012; 31(6):817-30. doi: 10.1016/j.clnu.2012.08.011. [PubMed: 23079762].

19. Falconer R, Skouras C, Carter T, Greenway L, Paisley AM. Preoperative fasting: current practice and areas for improvement. Updates Surg. 2014;66(1):31-9. doi: 10.1007/ s13304-013-0242-z. [PubMed: 24346767].

20. Ludwig RB, Paludo J, Fernandes D, Scherer F. Lesser time of preoperative fasting and early postoperative feeding are safe? Arq Bras Cir Dig. 2013;26(1):54-8. doi: 10.1590/s010267202013000100012. [PubMed: 23702872].

21. Manchikanti L, Malla Y, Wargo BW, Fellows B. Preoperative fasting before interventional techniques: is it necessary or evidence-based? Pain Physician. 2011;14(5):459-67. [PubMed: 21927050].

22. Stuart PC. The evidence base behind modern fasting guidelines. Best Pract Res Clin Anaesthesiol. 2006;20(3):45769. doi: 10.1016/j.bpa.2006.03.001. [PubMed: 17080696].

23. Helminen H, Branders $H$, Ohtonen P, Saarnio J. Effect of preoperative oral carbohydrate loading on recovery after day-case cholecystectomy: A randomised controlled trial. Eur J
Anaesthesiol. 2019;36(8):605-611. doi: 10.1097/EJA.00000 00000001002. [PubMed: 31021880].

24. Çakar E, Yilmaz E, Çakar E, Baydur H. The effect of preoperative oral carbohydrate solution intake on patient comfort: a randomized controlled study. I Perianesth Nurs. 2017;32(6):589-599. doi: 10.1016/j.jopan.2016.03.008. [PubMed: 29157765].

25. Nygren J, Thorell A, Jacobsson H, Larsson S, Schnell PO, Hylén $\mathrm{L}$, et al. Preoperative gastric emptying. Effects of anxiety and oral carbohydrate administration. Ann Surg. 1995;222(6):72834. doi: 10.1097/00000658-199512000-00006. [PubMed: 8526579].

26. Morimoto $Y$, Kinugawa T, Hayashi M, Iida T, Yamamoto $T$. Effects of preoperative oral carbohydrate intake on catabolism, nutrition and adipocytokines during minor surgery: A randomized, prospective, controlled clinical phase II trial. PLOS One. 2019;14(5):e0216525. doi: 10.1371/journal.pone.0216525. [PubMed: 31083704].

27. Rizvanović N, Nesek Adam V, Čaušević S, Dervišević $S$, Delibegović S. A randomised controlled study of preoperative oral carbohydrate loading versus fasting in patients undergoing colorectal surgery. Int J Colorectal Dis. 2019; 34(9):1551-1561. doi: 10.1007/s00384-019-03349-4. [PubMed: 31309323].

28. Liu B, Wang Y, Liu S, Zhao T, Zhao B, Jiang $\mathrm{X}$, et al. A randomized controlled study of preoperative oral carbohydrate loading versus fasting in patients undergoing elective craniotomy. Clin Nutr. 2019;38(5):2106-2112. doi: 10.1016/j.clnu.2018.11.008. [PubMed: 30497695].

29. Lee JS, Song Y, Kim JY, Park JS, Yoon DS. Effects of preoperative oral carbohydrates on quality of recovery in laparoscopic cholecystectomy: A randomized, double blind, placebocontrolled trial. World J Surg. 2018;42(10):3150-3157. doi: 10.1007/s00268-018-4717-4. [PubMed: 29915988]

30. Jodłowski T, Dobosz M. Preoperative fasting- is it really necessary? Pol Przegl Chir. 2014;86(2):100-5. doi: 10.2478/ pjs-2014-0019. [PubMed: 24670343].

31. Ozdemir F, Eti Z, Corman Dincer P, Gogus FY, Bekiroglu N. the effect of preoperative oral carbohydrate loading on stress response in patients undergoing major or minor surgery. Turkiye Klinikleri J Med Sci. 2011;31(6):1392-400. doi: 10.5336/medsci.2010-20548

32. Perrone F, da-Silva-Filho AC, Adôrno IF, Anabuki NT, Leal FS, Colombo T, et al. Effects of preoperative feeding with a whey protein plus carbohydrate drink on the acute phase response and insulin resistance. Nutr J. 2011;10:66. doi: 10.1186/14752891-10-66. [PubMed: 21668975].

33. Yildiz H, Gunal SE, Yilmaz G, Yucel S. Oral carbohydrate supplementation reduces preoperative discomfort in laparoscopic cholecystectomy. J Invest Surg. 2013;26(2):89-95. doi: 10.3109/08941939.2012.699998. [PubMed: 23547623]. 